\title{
Hepatic protein kinase B (Akt) -target of rapamycin (TOR)-signalling pathways and intermediary metabolism in rainbow trout (Oncorhynchus mykiss) are not significantly affected by feeding plant-based diets
}

\author{
Marine Lansard ${ }^{1,2,3}$, Stéphane Panserat ${ }^{1,2,3}$, Iban Seiliez ${ }^{1,2,3}$, Sergio Polakof ${ }^{1,2,3,4}$, Elisabeth Plagnes-Juan ${ }^{1,2,3,4}$, \\ Inge Geurden $^{1,2,3}$, Françoise Médale ${ }^{1,2,3}$, Sadasivam Kaushik ${ }^{1,2,3}$, Geneviève Corraze ${ }^{1,2,3}$ \\ and Sandrine Skiba-Cassy ${ }^{1,2,3 *}$ \\ ${ }^{1}$ INRA, UMR1067 Nutrition Aquaculture et Génomique, Pôle d'hydrobiologie, CD918, F-64310 St-Pée-sur-Nivelle, France \\ ${ }^{2}$ IFREMER, UMR1067 Nutrition Aquaculture et Génomique, F-29280 Plouzané, France \\ ${ }^{3}$ Université Bordeaux 1, UMR 1067 Nutrition Aquaculture et Génomique, F-33405 Talence, France \\ ${ }^{4}$ Laboratorio de Fisioloxía Animal, Departamento de Bioloxía Funcional Ciencias da saúde, Facultade de Bioloxía, Universidade \\ de Vigo, Vigo, Spain
}

(Received 9 March 2009 - Revised 11 June 2009 - Accepted 12 June 2009 - First published online 10 August 2009)

\begin{abstract}
The aim of the present study was to analyse the effects of partial or total replacement of fish meal (FM) and fish oil (FO) by a mixture of plant protein (PP) and a mixture of vegetable oils (VO) on the hepatic insulin-nutrient-signalling pathway and intermediary metabolism-related gene expression in rainbow trout (Oncorhynchus mykiss). Triplicate groups of fish were fed four practical diets containing graded levels of replacement of FM and FO by PP and VO for 12 weeks: diet 0/0 (100\% FM, 100\% FO); diet 50/50 (50\% FM and 50\% PP, $50 \%$ FO and $50 \%$ VO); diet 50/100 (50\% FM and 50\% PP, $100 \%$ VO); diet 100/100 (100\% PP, 100\% VO). Samplings were performed on trout starved for $5 \mathrm{~d}$ then refed with their allocated diet. In contrast to partial substitution (diet 50/50), total substitution of FM and FO (diet 100/100) led to significantly lower growth compared with diet 0/0. The insulin-nutrient-signalling pathway (protein kinase B (Akt), target of rapamycin (TOR), S6 protein kinase 1 (S6K1) and S6) was characterised in trout liver and found to be activated by refeeding. However, changes in diet compositions did not differentially affect the Akt-TOR-signalling pathway. Moreover, expression of genes encoding fructose-1,6-biphosphatase, mitochondrial phosphoenolpyruvate carboxykinase, glucokinase, pyruvate kinase and carnitine palmitoyl transferase 1 were not affected by refeeding or by dietary changes. Refeeding down- and up-regulated the expression of gluconeogenic glucose-6-phosphatase isoform 1 and lipogenic fatty acid synthase genes, respectively. Expression of both genes was also increased with partial replacement of FM and total replacement of FO (diet 50/100). These findings indicate that plant-based diets barely affect glucose and lipid metabolism in trout.
\end{abstract}

Insulin-signalling pathway: Plant-based diets: Hepatic gene expression: Rainbow trout

Teleosts in general are known to have high dietary protein and specific essential fatty acid requirements ${ }^{(1)}$. In intensively farmed fish, the indispensable amino acids and essential fatty acids are generally supplied by fish meal (FM) and fish oil (FO) derived from marine fishery resources ${ }^{(2)}$. Such a practice is considered controversial ${ }^{(3,4)}$ because fishery resources cannot meet the increasing demands for such feedstuffs, and reliance on wild fisheries thus needs to be reduced in order to ensure sustainable development of aquaculture. This has increased the interest in research into alternatives to FM and FO such as plant feedstuffs, i.e. plant proteins (PP) and vegetable oils $(\mathrm{VO})^{(5)}$. Compared with FM, most PP sources are characterised by relatively low protein content, amino acid imbalance, low palatability, presence of endogenous anti-nutritional factors and large amounts of carbohydrates ${ }^{(5,6)}$, and the fatty acid profiles of VO do not fulfil the essential fatty acid needs of fish ${ }^{(7-9)}$. Despite these disadvantages, much progress has been made in the use of plant products in aquafeeds to replace either FM by PP or FO by $\mathrm{VO}^{(7,10-17)}$. However, recent studies have revealed changes in patterns of expression of several genes involved in $\mathrm{N}$ and fat metabolism and their corresponding protein profiles in the livers of salmonids fed feeds with low levels of FO or $\mathrm{FM}^{(18-21)}$. These findings strongly suggest changes in intermediary metabolism as a consequence of high levels of plant feedstuffs in the diets of teleosts $^{(22)}$. The aim of the present study was therefore to

\footnotetext{
Abbreviations: Akt, protein kinase B; CPT1, carnitine palmitoyl transferase 1; diet 0/0, fish meal and fish oil as the main protein and fat sources; diet 50/50, 50\% supply of proteins by a mixture of plant protein sources and $50 \%$ of fish oil substituted by a mixture of vegetable oil; diet $50 / 100$, $50 \%$ supply of proteins by a mixture of plant protein sources and all fish oil substituted by vegetable oil; diet 100/100, total replacement of both fish meal and fish oil by plant protein and vegetable oil; EF1 $\alpha$, elongation factor 1 $\alpha$; FAS, fatty acid synthase; FBPase, fructose-1,6-biphosphatase; FM, fish meal; FO, fish oil; GK, glucokinase; G6Pase, glucose-6-phosphatase; PEPCK, phosphoenolpyruvate carboxykinase; PK, pyruvate kinase; PP, plant protein; TOR, target of rapamycin; VO, vegetable oil.

* Corresponding author: Dr Sandrine Skiba-Cassy, fax + 335595451 52, email skiba@st-pee.inra.fr
} 
analyse the effects of partial or total combined replacement of FM and FO by a blend of plant ingredients on intermediary metabolism, which has yet to be fully explored in fish, even in salmonids. The present study was focused on the liver since it is the centre of intermediary metabolism and lipogenesis.

The liver intermediary metabolism in mammals is mainly regulated by insulin and nutrients. Insulin acts through a tyrosine kinase membrane receptor. When activated by insulin binding, tyrosine kinase recruits and phosphorylates intracellular substrates known as IRS (insulin receptor substrates). Phosphorylated IRS are used as docking sites for proteins which then transmit the insulin signal through several molecules, including successively the phosphatidylinositol-3kinase and protein kinase B (Akt) ${ }^{(23)}$. Through this pathway insulin regulates hepatic gene expression, especially that of intermediary metabolism. Gluconeogenic genes are mainly under insulin control ${ }^{(24)}$. Indeed, in mammals, insulin inhibits expression of glucose-6-phosphatase (G6Pase), and phosphoenolpyruvate carboxykinase (PEPCK) enzymes at the transcriptional level ${ }^{(24,25)}$ through the activation of the protein $\mathrm{Akt}^{(26,27)}$, a critical node in the insulin-signalling pathway ${ }^{(23)}$. In the same way, insulin regulation of fatty acid synthase (FAS) transcription in mammals is mediated by the phosphatidylinositol-3-kinase-Akt-signalling pathway $^{(25)}$. However, increasing evidence has emerged in recent years to show that nutrients are able to regulate hepatic gene expression in a transcriptional manner. Indeed, glycolytic and lipogenic genes are reciprocally regulated by glucose and fatty acids in the liver ${ }^{(28)}$. Nutrients may also interact with insulin function. For example, excessive levels of amino acids have detrimental effects on glucose homeostasis by promoting insulin resistance and increasing gluconeogenesis ${ }^{(29)}$, which could be due to the activation of complex 1 of the mammalian target of rapamycin (mTORC1). mTORC1 is regulated by both nutrients (i.e. amino acids) and growth factors (i.e. insulin) and plays a key role in the control of cell growth and protein translation through the subsequent activation of p70 ribosomal S6 protein kinase 1 and ribosomal protein $\mathrm{S} 6^{(30)}$. Moreover, recent findings have indicated that activation of mTORC1 also contributes to the regulation of insulin target gene expression ${ }^{(31)}$. No findings have been published to date concerning the nutritional regulation of Akt-TOR pathways in the livers of teleosts, normally requiring high dietary levels of amino acid.

The aim of the present study was therefore to address whether diet substitution could affect the nutrient and insulin-signalling pathways and metabolism-related gene expression, on which very little information is available for any teleost. Several key enzymes of glucose and lipid metabolism known to be under insulin control in mammals and in fish were analysed ${ }^{(32)}$. Gluconeogenesis was investigated by studying the gene expression of G6Pase, fructose-1,6-biphosphatase (FBPase) and PEPCK. We also analysed mRNA levels of glucokinase $(\mathrm{GK})$ and pyruvate kinase $(\mathrm{PK})$ which catalyse the phosphorylation of glucose and the conversion of phosphoenolpyruvate to pyruvate, the first and the final steps in glycolysis, respectively ${ }^{(33)}$. We also investigated the gene expression levels of two enzymes involved in fatty acid metabolism: (i) FAS, which is a key enzyme in fatty acid synthesis and promotes the synthesis of palmitate, through the condensation of malonyl-CoA and
acetyl-CoA ${ }^{(34)}$; (ii) carnitine palmitoyl transferase 1 (CPT1), which is responsible for the entry of long-chain fatty acids into the mitochondria and is considered to be a rate-limiting enzyme of fatty acid $\beta$-oxidation.

\section{Experimental methods}

Studies with animals were carried out in accordance with legislation governing the ethical treatment of animals, and investigators were certified by the French Government to carry out animal experiments (authority: Prefecture of Pyrénées Atlantiques, 64000 Pau, for INRA St Pée-surNivelle). Animal experiments were in accordance with national law Decret no. 2001-464 of 29 May 2001, as applicable in INRA according to INRA no. 2002-36, of 4 April 2002.

\section{Feeding trial}

In order to investigate the effects of partial or total replacement of FM and FO by a mixture of PP and VO, we used

Table 1. Composition of the four diets with the proportions of plant protein (PP) and the proportions of vegetable oil (VO) indicated for each diet

\begin{tabular}{|c|c|c|c|c|}
\hline Diet (PP/VO)... & $0 / 0$ & $50 / 50$ & $50 / 100$ & $100 / 100$ \\
\hline \multicolumn{5}{|l|}{ Ingredients (\%) } \\
\hline Fish meal LT (CP 70\%)* & 59 & 29 & 29 & - \\
\hline Maize gluten meal (CP $57 \%) \dagger$ & - & 20 & 20 & 20 \\
\hline Soyabean meal (CP $46 \%) \dagger$ & - & 8 & 8 & $15 \cdot 4$ \\
\hline Wheat gluten (CP $78 \%) \ddagger$ & - & $7 \cdot 8$ & $7 \cdot 8$ & 26 \\
\hline Maize§ & 7 & 7 & 7 & 7 \\
\hline Extruded whole wheat $†$ & 12 & $3 \cdot 2$ & $3 \cdot 2$ & 0.1 \\
\hline Fish oil* & 19 & 11 & - & - \\
\hline Rapeseed oill| & - & $5 \cdot 5$ & 11 & 11.6 \\
\hline Linseed oil| & - & $2 \cdot 2$ & $4 \cdot 4$ & $4 \cdot 6$ \\
\hline Palm oill & - & $3 \cdot 3$ & $6 \cdot 6$ & 7 \\
\hline Soyabean lecithin & - & - & - & 1 \\
\hline L-Lysine** & - & - & - & $1 \cdot 2$ \\
\hline L-Arginine ${ }^{\star \star}$ & - & - & - & 0.1 \\
\hline $\mathrm{CaHPO}_{4} \cdot 2 \mathrm{H}_{2} \mathrm{O}(18 \% \mathrm{P})$ & - & - & - & 3 \\
\hline Astaxanthin†† & 0.03 & 0.04 & 0.05 & 0.03 \\
\hline Mineral premix㧊 & 1 & 1 & 1 & 1 \\
\hline Vitamin premix§§ & 1 & 1 & 1 & 1 \\
\hline \multicolumn{5}{|l|}{ Analytical composition } \\
\hline DM (\%) & $94 \cdot 1$ & $94 \cdot 3$ & 93.9 & 90.9 \\
\hline CP (\% DM) & $45 \cdot 9$ & $46 \cdot 7$ & $45 \cdot 9$ & $44 \cdot 4$ \\
\hline Crude fat (\% DM) & $26 \cdot 6$ & $27 \cdot 4$ & $27 \cdot 6$ & $27 \cdot 8$ \\
\hline Crude starch (\% DM) & $12 \cdot 1$ & $10 \cdot 4$ & $11 \cdot 2$ & $11 \cdot 3$ \\
\hline Gross energy (kJ/g DM) & $24 \cdot 1$ & $25 \cdot 4$ & $25 \cdot 5$ & $25 \cdot 7$ \\
\hline
\end{tabular}

$\mathrm{CP}$, crude protein.

* Sopropêche (Lorient, France).

† Inzo (Argentan, France).

$\ddagger$ Roquette (Lestrem, France).

$\S$ Lacadee Agro Industrie (Mont, France).

II Daudruy (Dunkerque, France).

ๆ Louis François (Saint Maur, France).

${ }^{\star \star}$ Eurolysine (Paris, France).

†† Carophyll pink (DSM, Courbevoie, France).

$\ddagger \ddagger$ Supplied the following (per $\mathrm{kg}$ diet): calcium carbonate $(40 \% \mathrm{Ca}), 2.15 \mathrm{~g}$; magnesium hydroxide $(60 \% \mathrm{Mg}), 1.24 \mathrm{~g}$; potassium chloride, $0.9 \mathrm{~g}$; ferric citrate, $0.2 \mathrm{~g}$; potassium iodide, $4 \mathrm{mg}$; sodium chloride, $0.4 \mathrm{~g}$; calcium hydrogen phosphate, $50 \mathrm{~g}$; copper sulfate, $0.3 \mathrm{mg}$; zinc sulfate, $40 \mathrm{mg}$; cobalt sulfate, $2 \mathrm{mg}$; manganese sulfate, $30 \mathrm{mg}$; sodium selenite, $0.3 \mathrm{mg}$.

$\S \S$ Supplied the following $(\mathrm{mg} / \mathrm{kg}$ diet): retinyl acetate, 2.58; DL-cholecalciferol, 0.037 ; DL- $\alpha$-tocopheryl acetate, 30; menadione sodium bisulfite, 2.5; thiamin 7.5; riboflavin, 15; pyridoxine, 7.5; nicotinic acid, 87.5; folic acid, 2.5; calcium pantothenate, 2.5; vitamin $\mathrm{B}_{12}, 0.025$; ascorbic acid, 250; inositol, 500; biotin 1.25; choline chloride, 500 . 
juvenile rainbow trout (Oncorhynchus mykiss), having a mean initial body weight of 121 (SD 2) g, reared in our experimental fish farm facilities (INRA, Donzacq, France) at $18^{\circ} \mathrm{C}$ under natural photoperiod conditions. Trout were distributed into twelve circular tanks (500 litres; three tanks per diet) in groups of 100 fish each. Triplicate groups of fish were randomly allocated to one of the four isonitrogenous, isolipidic and isoenergetic diets, formulated and manufactured in our experimental facilities of Donzacq, France (Table 1) and fed for 12 weeks. Diets were constituted as follows and named by the percentage of plant feedstuff (PP/VO) incorporated: diet $0 / 0$, in which FM and FO were the main protein and fat sources; diet 50/50, corresponding to $50 \%$ supply of proteins by a mixture of PP sources and $50 \%$ of FO substituted by a mixture of VO; diet 50/100, comparable with diet 50/50, except that FO was totally replaced by VO; diet 100/100, corresponding to total replacement of both FM and FO by PP and VO. Each diet was distributed by hand to visual satiation for 6 or $7 \mathrm{~d}$ and feed consumption was recorded every week. To follow growth and feed utilisation, fish were counted and group weighed every 3 weeks, and on the last day of the experiment the final body weight was measured. According to their size $( \pm 450 \mathrm{~g})$, fish were left unfed for $5 \mathrm{~d}$ in order to obtain basal levels of plasma metabolites, reached later in fish than in mammals due to their slower transit and longer gastric emptying time at low temperature compared with endothermic animals. This fasting period also contributed to homogeneity of the metabolic response of all the fish within the same group. Fish were refed a single meal to visual satiation of their allocated diet and sampled $(n 6) 2 \mathrm{~h}$ after the meal for the signalling analysis (short-term regulation) and $8 \mathrm{~h}$ after the meal for molecular studies (long-term regulation). Six fish from each dietary group were sampled before refeeding and served as controls. Blood was collected from the caudal vein using a syringe pre-treated with a solution containing $4 \%$ $\mathrm{NaF}$ and $4 \%$ potassium oxalate, then centrifuged, and plasma was kept frozen at $-20^{\circ} \mathrm{C}$ until further analysis. Liver samples were collected, snap-frozen in liquid $\mathrm{N}_{2}$ and then stored at $-80^{\circ} \mathrm{C}$ before further mRNA and protein analyses.

\section{Plasma metabolite levels}

Plasma glucose, TAG and NEFA levels were measured with Glucose RTU (BioMérieux, Marcy l'Etoile, France), PAP 150 (BioMérieux) and NEFA C (Wako Chemicals $\mathrm{GmbH}$, Neuss, Germany) kits, respectively, according to the recommendations of each manufacturer.

\section{Gene expression analysis}

Total RNA samples were extracted from livers of $8 \mathrm{~h}$ refed trout, using Trizol reagent (Invitrogen, Carlsbad, CA, USA) according to the manufacturer's recommendations. A quantity of $1 \mu \mathrm{g}$ of the resulting total RNA was reverse transcribed into cDNA using the SuperScript ${ }^{\mathrm{TM}}$ III RNaseH- RT kit (Invitrogen) and oligo dT primers (Promega, Charbonnières, France) according to the manufacturers' instructions. Target gene expression levels were determined by quantitative RTPCR using specific real-time PCR primers (Table 2). To avoid amplification of genomic DNA, when possible, primer pairs included one intron-spanning oligonucleotide. Quantitative RT-PCR was carried out on an $\mathrm{iCycler}_{\mathrm{iQ}}{ }^{\mathrm{TM}}$ real-time PCR detection system (Bio-Rad, Hercules, CA, USA) using $\mathrm{iQ}^{\mathrm{TM}}$ SYBR $^{\circledR}$ Green Supermix. mRNA levels of G6Pase isoforms 1 and 2, FBPase, mitochondrial PEPCK, GK, PK, FAS and CPT1 isoforms A and B were evaluated. Elongation factor $1 \alpha(\mathrm{EF} 1 \alpha)$ was employed as a non-regulated reference gene, as previously used in rainbow trout. No changes in EF1 $\alpha$ gene expression were observed in our studies (data not shown). PCR was performed using $10 \mu \mathrm{l}$ of the diluted cDNA mixed with 5 pmol of each primer in a final volume

Table 2. Primers used to amplify rainbow trout (Oncorhynchus mykiss) target genes by real-time RT-PCR

\begin{tabular}{|c|c|c|c|c|}
\hline Gene & Primer sequences & $\begin{array}{l}\text { Hybridisation } \\
\text { temperature }\left({ }^{\circ} \mathrm{C}\right)\end{array}$ & $\begin{array}{l}\text { Amplicon size } \\
\text { (bp) }\end{array}$ & $\begin{array}{l}\text { GenBank or Sigenae } \\
\text { accession no. }\end{array}$ \\
\hline $\mathrm{EF} 1 \alpha$ & $\begin{array}{l}\text { F: 5'-TCCTCTTGGTCGTTTCGCTG-3' } \\
\text { R: 5'-ACCCGAGGGACATCCTGTG-3' }\end{array}$ & $59^{\circ} \mathrm{C}$ & 159 & AF498320 \\
\hline GK & $\begin{array}{l}\text { F: 5'-TGAAGGATCAGAGGTGGGTGATT-3' } \\
\text { R: 5'-GAAGGTGAAACCCAGAGGAAGC-3' }\end{array}$ & $59^{\circ} \mathrm{C}$ & 253 & AF135403 \\
\hline $\mathrm{PK}$ & $\begin{array}{l}\mathrm{F}: 5^{\prime} \text {-CCATCGTCGCGGTAACAAGA-3' } \\
\text { R: 5'-ACATAGGAAAGGCCAGGGGC-3' }\end{array}$ & $59^{\circ} \mathrm{C}$ & 158 & AF246146 \\
\hline MPEPCK & $\begin{array}{l}\text { F: 5'-GTTGGTGCTAAAGGGCACAC-3' } \\
\text { R: 5'-CCCGTCTTCTGATAAGTCCAA-3' }\end{array}$ & $59^{\circ} \mathrm{C}$ & 149 & AF246149 \\
\hline G6Pase-1 & $\begin{array}{l}\text { F: 5'-CTCAGTGGCGACAGAAAGG-3' } \\
\text { R: 5'-TACACAGCAGCATCCAGAGC-3' }\end{array}$ & $55^{\circ} \mathrm{C}$ & 77 & tcay0019b.d.18_3.1.s.om.8.1-1693 \\
\hline G6Pase-2 & $\begin{array}{l}\text { F: 5'-TAGCCATCATGCTGACCAAG-3' } \\
\text { R: 5'-CAGAAGAACGCCCACAGAGT-3' }\end{array}$ & $55^{\circ} \mathrm{C}$ & 82 & AF120150 \\
\hline FBPase & 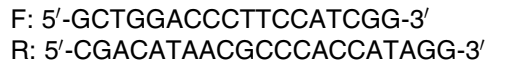 & $59^{\circ} \mathrm{C}$ & 182 & AF333188 \\
\hline FAS & $\begin{array}{l}\text { F: 5'-TGATCTGAAGGCCCGTGTCA-3' } \\
\text { R: 5'-GGGTGACGTTGCCGTGGTAT-3' }\end{array}$ & $60^{\circ} \mathrm{C}$ & 161 & tcab0001c.e.06_5.1.s.om.8 \\
\hline CPT1A & $\begin{array}{l}\text { F: 5'-TCGATTTTCAAGGGTCTTCG-3' } \\
\text { R: 5'-CACAACGATCAGCAAACTGG-3' }\end{array}$ & $55^{\circ} \mathrm{C}$ & 166 & AF327058 \\
\hline CPT1B & $\begin{array}{l}\text { F: 5'-CCCTAAGCAAAAAGGGTCTTCA-3' } \\
\text { R: 5'-CATGATGTCACTCCCGACAG-3' }\end{array}$ & $55^{\circ} \mathrm{C}$ & 149 & AF606076 \\
\hline
\end{tabular}

F, forward primer; R, reverse primer. EF1 $\alpha$, elongation factor $1 \alpha$; GK, glucokinase; PK, pyruvate kinase; mPEPCK, phosphoenolpyruvate carboxykinase, mitochondrial isoform; G6Pase-1, glucose 6-phosphatase 1; G6Pase-2, glucose 6-phosphatase 2; FBPase, fructose 1,6-bisphosphatase; FAS, fatty acid synthase; CPT1A, carnitine palmitoyltransferase $1 \mathrm{~A} ; \mathrm{CPT} 1 \mathrm{~B}$, carnitine palmitoyltransferase $1 \mathrm{~B}$. 
of $25 \mu \mathrm{l}$. The PCR protocol was initiated at $95^{\circ} \mathrm{C}$ for $3 \mathrm{~min}$ for initial denaturation of the cDNA and hot-start $\mathrm{iTaq}^{\mathrm{TM}}$ DNA polymerase activation and continued with a two-step amplification programme $\left(20 \mathrm{~s}\right.$ at $95^{\circ} \mathrm{C}$ followed by $30 \mathrm{~s}$ at specific primer hybridisation temperature) repeated forty times. Melting curves were systematically monitored (temperature gradient at $0.5^{\circ} \mathrm{C}$ per $10 \mathrm{~s}$ from 55 to $94^{\circ} \mathrm{C}$ ) at the end of the last amplification cycle to confirm the specificity of the amplification reaction. The different PCR products were initially checked by sequencing to confirm the nature of the amplicon. Each PCR run included replicate samples (duplicate of reverse transcription and PCR amplification, respectively) and negative controls (RT- and RNA-free samples, respectively).

Relative quantification of target gene expression was performed using the mathematical model described by Pfaffl ${ }^{(35)}$. The relative expression ratio $(\mathrm{R})$ of a target gene was calculated based on real-time PCR efficiency (E) and the cycle threshold deviation $(\Delta \mathrm{CT})$ of the unknown sample $v$. a control sample and expressed in comparison with the EF1 $\alpha$ reference gene:

$$
R=\frac{\left(\left(\mathrm{E}_{\text {target gene }}\right) \Delta \mathrm{CT}_{\text {target gene }}(\text { control }- \text { sample })\right)}{\left(\left(\mathrm{E}_{\mathrm{EF} 1 \alpha}\right) \Delta \mathrm{CT} \mathrm{T}_{\mathrm{EF} 1 \alpha}(\text { control }- \text { sample })\right)} .
$$

PCR efficiency (E) was measured by the slope of a standard curve using serial dilutions of cDNA. PCR efficiency values ranged between 1.90 and 2 .

\section{Protein extraction and Western blotting}

Frozen livers $(300 \mathrm{mg})$ from $2 \mathrm{~h}$ refed trout were homogenised on ice with an Ultraturrax homogeniser in a buffer containing $150 \mathrm{~mm}-\mathrm{NaCl}, \quad 10 \mathrm{~mm}$-2-amino-2-hydroxymethyl-propane-1, 3-diol, 1 mM-ethylene-glycol-bis(a-aminoethyl)- $N, N, N^{\prime}, N^{\prime}$-tetraacetic acid, 1 mm-EDTA (pH 7.4), 100 mM-sodium fluoride, $4 \mathrm{~mm}$-sodium pyrophosphate, $2 \mathrm{~mm}$-sodium orthovanadate, $1 \%$ Triton X-100, 0.5\% NP-40-Igepal and a protease inhibitor cocktail (Roche, Basel, Switzerland). Homogenates were centrifuged at $1000 \mathrm{~g}$ for $30 \mathrm{~min}$ at $4^{\circ} \mathrm{C}$ and supernatant fractions were then centrifuged for $45 \mathrm{~min}$ at $150000 \mathrm{~g}$. The resulting supernatant fractions were sampled and stored at $-80^{\circ} \mathrm{C}$. Protein concentrations were determined using the Bio-Rad protein assay kit (Bio-Rad, Hercules, CA, USA). Lysates $(20 \mu \mathrm{g}$ protein) were subjected to SDS-PAGE and Western blotting using the appropriate antibody. All antibodies used were obtained from Cell Signaling Technologies (Ozyme, Saint Quentin Yvelines, France). Rabbit anti-phospho-Akt $\left(\mathrm{Ser}^{473}\right)$ and Akt antibodies were directed against synthetic peptides corresponding to residues surrounding phosphorylated Ser ${ }^{473}$ of mouse Akt and the carboxyterminal sequence of mouse Akt, respectively. Rabbit anti-phospho-mTOR $\left(\operatorname{Ser}^{2448}\right)$, antimTOR, antiphospho-S6 protein kinase $1\left(\mathrm{Thr}^{389}\right)$, anti-S6 protein kinase 1, anti-phospho-S6 (Ser ${ }^{235 / 236}$ ) and anti-S6 were directed against synthetic human peptides. These antibodies have been shown to successfully cross-react with rainbow trout proteins of interest ${ }^{(36)}$. After washing, membranes were incubated with an IRDye Infrared secondary antibody (LI-COR Inc. Biotechnology, Lincoln, NE, USA). Bands were visualised by Infrared Fluorescence using the Odyssey ${ }^{\circledR}$ Imaging System (LI-COR Inc. Biotechnology) and quantified by Odyssey ${ }^{\circledR}$ Infrared imaging system software (version 1.2; LI-COR Inc. Biotechnology).

\section{Statistical analysis}

Results of growth performance were expressed as mean values and standard deviations (three tanks) and analysed by$$
\text { (A) }
$$
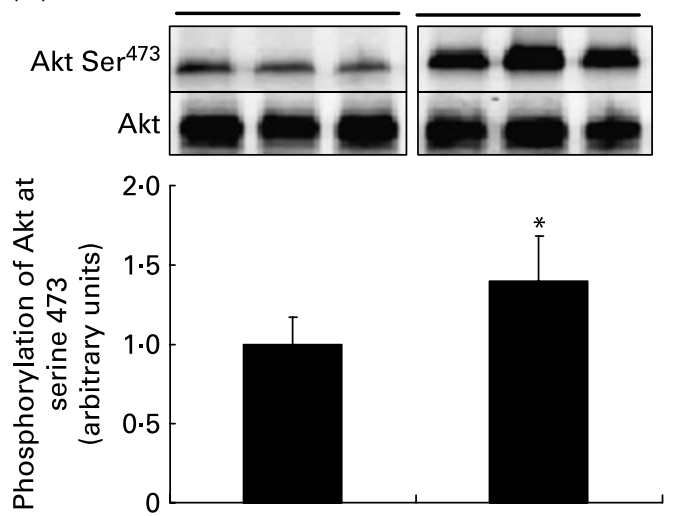

(B)
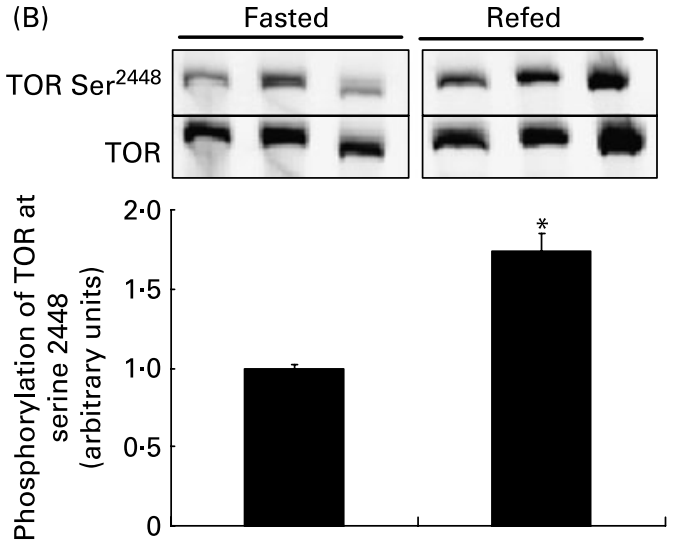

$$
\text { (C) }
$$
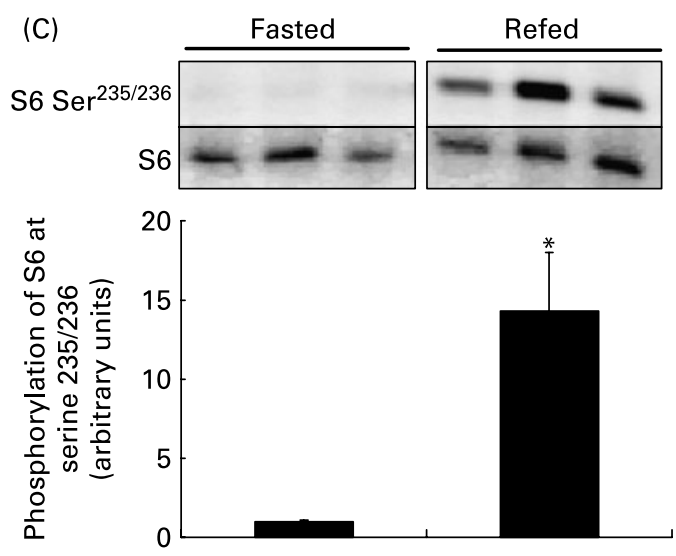

Fig. 1. Phosphorylation of protein kinase $B(A k t)$ at $\operatorname{Ser}^{473}(A)$, target of rapamycin (TOR) at $\operatorname{Ser}^{2448}(B)$ and $S 6$ at $\operatorname{Ser}^{235 / 236}(C)$ in the livers of rainbow trout (Oncorhynchus mykiss) deprived of food for $5 \mathrm{~d}$, refed ad libitum and sampled $2 \mathrm{~h}$ after administration of the $100 \%$ fish meal-100\% fish oil diet (diet $0 / 0$ ). The gel was loaded with $40 \mu \mathrm{g}$ of total protein per lane. Phosphorylation levels of Akt at $\mathrm{Ser}^{473}$, Akt, TOR at Ser ${ }^{2448}$, TOR, S6 at $\mathrm{Ser}^{235 / 236}$ and S6 were quantified and data were normalised to total amounts of Akt, TOR and S6, respectively. Western blots were performed on six individual samples and similar results were obtained; representative blots are shown. Results are means ( $n 6)$, with standard errors represented by vertical bars. * Mean value was significantly different from that of the fasted group $(P<0.05$; Mann-Whitney test). 
one-way ANOVA. Means were compared by the StudentNewman-Keuls comparison test. Results of plasma metabolite levels, protein phosphorylation and gene expression analysis were expressed as mean values with their standard errors ( $n$ 6) and analysed by the Mann-Whitney and Kruskall-Wallis non-parametric tests. For all statistical analyses, the level of significance was set at $P<0 \cdot 05$.

\section{Results}

Characterisation and regulation of the protein kinase $B$-target of rapamycin-signalling pathway

As illustrated in Fig. 1, proteins of the insulin-signalling pathway including Akt, TOR, and the ribosomal protein S6 were

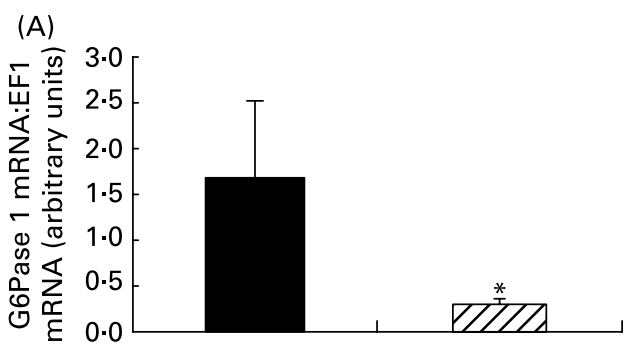

(C)
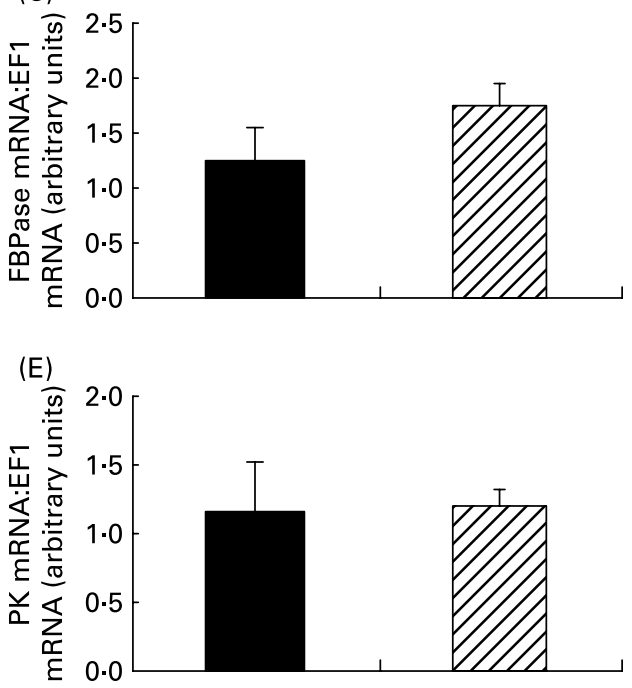

(G)

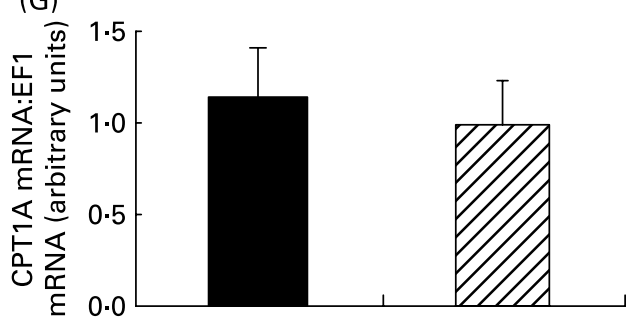

identified in rainbow trout liver. Phosphorylation of Akt $\left(\mathrm{Ser}^{473}\right)$, TOR $\left(\mathrm{Ser}^{2448}\right)$ and S6 $\left(\mathrm{Ser}^{235 / 236}\right)$ was significantly increased $(P<0.005)$ in the livers of refed fish compared with $5 \mathrm{~d}$ fasted fish. Levels of total Akt, TOR and S6 were not significantly modified by refeeding.

\section{Postprandial regulation of metabolism-related hepatic gene expression}

The effects of refeeding with the standard diet (diet 0/0) on G6Pase isoforms 1 and 2, FBPase, mitochondrial PEPCK, GK, PK, FAS, CPT1A and CPT1B gene expression in the liver are presented in Fig. 2. In $8 \mathrm{~h}$ refed fish, G6Pase-1 gene expression was 3 -fold decreased $(P<0.05)$ and FAS gene expression was 4 -fold increased $(P=0.002)$ compared

(B)

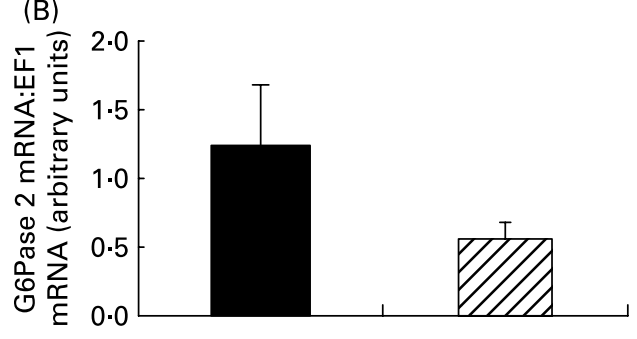

(D)
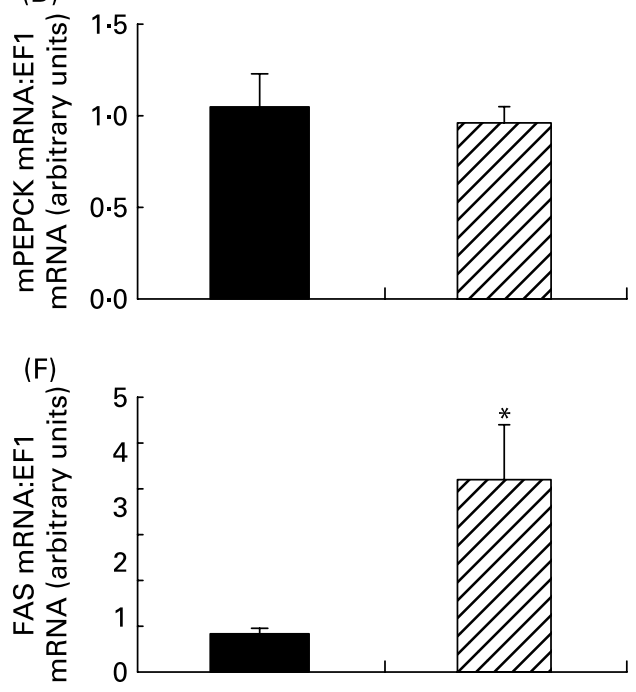

(H)

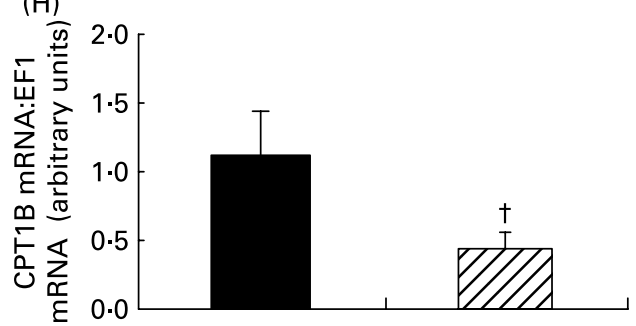

Fig. 2. Levels of expression of mRNA encoding hepatic genes in the livers of rainbow trout (Oncorhynchus mykiss) deprived of food for $5 \mathrm{~d}(\mathbf{\square})$, refed ad libitum and sampled $8 \mathrm{~h}$ after administration of the $100 \%$ fish meal-100\% fish oil diet (diet 0/0) (ש्E). Glucose 6-phosphatase isoform 1 (G6Pase-1) (A), glucose 6-phosphatase isoform 2 (G6Pase-2) (B), fructose 1,6-bisphosphatase (FBPase) (C), mitochondrial phosphoenolpyruvate carboxykinase (mPEPCK) (D), pyruvate kinase $(\mathrm{PK})(\mathrm{E})$, fatty acid synthase $(\mathrm{FAS})(\mathrm{F})$, carnitine palmitoyltransferase 1 isoform $A(C P T 1 A)(G)$ and carnitine palmitoyltransferase 1 isoform $B(C P T 1 B)(H)$ mRNA levels were estimated using real-time RT-PCR. Expression values were normalised with elongation factor $1 \alpha(E F 1 \alpha)$-expressed transcripts. Results are means $(n 6)$, with standard errors represented by vertical bars. * Mean value was significantly different from that of the fasted group $(P<0.05$; Mann-Whitney test). $†$ Mean value was marginally different from that of the fasted group $(P=0.06$; Mann-Whitney test). 
with fasted fish. No significant changes were noted for the other genes. GK mRNA levels are not reported in Fig. 2, since expression of GK was close to the limit of real-time PCR detection in all fish of the group.

Effects on rainbow trout of partial or total replacement of fish meal and fish oil by plant ingredients in the diet

After the 12-week growth trial, fish fed with diet 100/100 exhibited the lowest final body weight (Table 3). Fish fed with diet 50/100 displayed significantly lower final body weight in comparison with fish fed diet $0 / 0$ whereas fish fed with diet 50/50 showed no significant difference from those fed with diet $0 / 0$. Feed efficiency in trout fed with diet $100 / 100$ was significantly lower than in the other three groups and feed intake significantly decreased with graded increases in the inclusion of PP and VO in diets.

Findings on postprandial plasma glucose, NEFA and TAG levels are presented in Table 3. Plasma glucose levels increased slightly between 2 and $8 \mathrm{~h}$ after a meal in each dietary group, and no difference in plasma glucose levels was observed between the four groups 2 or $8 \mathrm{~h}$ after feeding. Plasma NEFA levels showed a significant increase between 2 and $8 \mathrm{~h}$ only in fish fed with diet $0 / 0$. On the other hand, there was no difference between the effects of diets $2 \mathrm{~h}$ after a meal, whereas $8 \mathrm{~h}$ after refeeding, trout fed with diet $0 / 0$ displayed significantly higher plasma NEFA levels than those fed with diet 50/50. Moreover, there was no difference in plasma TAG levels at either sampling time between the four groups. There was only a significant increase in plasma TAG levels between 2 and $8 \mathrm{~h}$ in fish fed diet 50/50.
Phosphorylated forms of Akt, TOR and S6 were detected in the livers of rainbow trout refed with each of the four diets (Fig. 3). At $2 \mathrm{~h}$ after refeeding, phosphorylation levels of Akt $\left(\mathrm{Ser}^{473}\right)$, TOR $\left(\mathrm{Ser}^{2448}\right)$ and S6 $\left(\operatorname{Ser}^{235 / 236}\right)$ displayed no significant differences between the four dietary groups (Fig. 3).

Hepatic mRNA levels of G6Pase-1 and G6Pase-2, FBPase, mitochondrial PEPCK, GK, PK, CPT1A and CPT1B and FAS were estimated in each group $8 \mathrm{~h}$ after refeeding (Fig. 4). Fish fed with diet 50/100 displayed significant up-regulation of G6Pase-2 only compared with fish fed diet 50/50, and upregulation of G6Pase-1 and FAS gene expression compared with fish fed the other three experimental diets. No significant difference between dietary groups was found for the other genes analysed.

\section{Discussion}

In the context of sustainable aquaculture, partial or total replacement of FM and FO by plant products has been the subject of several studies in many fish species ${ }^{(22)}$. Nevertheless, no study has to date investigated the effects of total substitution of FM and FO by PP and VO in fish diets. The aim of the present study was thus to analyse the possible physiological and hepatic metabolic consequences of such dietary substitutions in rainbow trout.

In the present study in rainbow trout we found that up to $50 \%$ replacement of dietary FM and FO by plant ingredients had no significant consequences on final body weight. On the other hand, total substitution of fish products by plant products led to reduced growth and feed utilisation. These results are in line with some recent studies on Atlantic salmon ${ }^{(37)}$ where fish

Table 3. Growth performance and plasma parameters measured over the 12-week feeding trial (Mean values and standard deviations)

\begin{tabular}{|c|c|c|c|c|c|c|c|c|}
\hline \multirow[t]{2}{*}{ Diet... } & \multicolumn{2}{|c|}{$0 / 0$} & \multicolumn{2}{|c|}{$50 / 50$} & \multicolumn{2}{|c|}{$50 / 100$} & \multicolumn{2}{|c|}{$100 / 100$} \\
\hline & Mean & SD & Mean & SD & Mean & SD & Mean & SD \\
\hline \multicolumn{9}{|c|}{ Zootechnical parameters (three tanks with 100 fish per tank per group) } \\
\hline IBW (g) & $121 \cdot 7$ & 1.5 & $121 \cdot 5$ & 1.4 & 121 & 3.6 & $121 \cdot 7$ & $3 \cdot 8$ \\
\hline FBW $(g)$ & $509 \cdot 10^{a}$ & $7 \cdot 10$ & $489 \cdot 20^{\mathrm{a}, \mathrm{b}}$ & 4.40 & $466^{b}$ & $25 \cdot 70$ & $427 \cdot 2^{c}$ & $2 \cdot 80$ \\
\hline SGR† & $1.93^{\mathrm{a}}$ & 0.03 & $1.88^{\mathrm{b}}$ & 0.01 & $1 \cdot 82^{\mathrm{C}}$ & 0.03 & $1 \cdot 70^{\mathrm{d}}$ & 0.03 \\
\hline Feed efficiency & $1 \cdot 17^{\mathrm{a}}$ & 0.04 & $1 \cdot 14^{\mathrm{a}}$ & 0.02 & $1 \cdot 14^{\mathrm{a}}$ & 0.01 & $1.03^{b}$ & 0.01 \\
\hline Feed intake§ & $5 \cdot 45^{\mathrm{a}}$ & 0.13 & $4 \cdot 50^{\mathrm{b}}$ & 0.02 & $4 \cdot 48^{b}$ & 0.02 & $4 \cdot 94^{b}$ & 0.04 \\
\hline \multicolumn{9}{|c|}{ Plasma parameters (six fish per group)\| } \\
\hline \multicolumn{9}{|c|}{ Glucose $(g / l)$} \\
\hline $2 \mathrm{~h}$ & 0.79 & 0.18 & 0.82 & 0.12 & 0.71 & 0.06 & 0.89 & 0.11 \\
\hline $8 \mathrm{~h}$ & $1 \cdot 09^{*}$ & 0.27 & $1.09^{*}$ & 0.16 & $0.95^{*}$ & 0.22 & $1 \cdot 39^{*}$ & 0.40 \\
\hline \multicolumn{9}{|l|}{ NEFA $(g / l)$} \\
\hline $2 \mathrm{~h}$ & 0.18 & 0.06 & 0.15 & 0.03 & 0.19 & 0.07 & 0.22 & 0.07 \\
\hline $8 \mathrm{~h}$ & $0.27^{a *}$ & 0.07 & $0 \cdot 16^{b}$ & 0.04 & $0.22^{a, b}$ & 0.10 & $0.24^{a, b}$ & 0.02 \\
\hline \multicolumn{9}{|l|}{ TAG (g/l) } \\
\hline $2 \mathrm{~h}$ & 1.68 & 0.51 & 1.86 & 1.05 & 1.55 & 0.55 & 1.32 & 0.39 \\
\hline $8 \mathrm{~h}$ & $2 \cdot 27$ & $1 \cdot 34$ & $3 \cdot 71^{*}$ & 1.53 & $2 \cdot 37$ & $1 \cdot 12$ & 2.03 & 0.87 \\
\hline
\end{tabular}

Diet $0 / 0$, fish meal and fish oil as the main protein and fat sources; diet $50 / 50,50 \%$ supply of proteins by a mixture of plant protein sources and $50 \%$ of fish oil substituted by a mixture of vegetable oil; diet $50 / 100,50 \%$ supply of proteins by a mixture of plant protein sources and all fish oil substituted by vegetable oil; diet 100/100, total replacement of both fish meal and fish oil by plant protein and vegetable oil; IBW, initial body weight; FBW, final body weight; SGR, specific growth rate.

${ }_{a, b, c, d}$ Mean values within a row with unlike superscript letters were significantly different $(P<0.05$; ANOVA followed by Student-NewmanKeuls mean comparison and Kruskal-Wallis non-parametric test for zootechnical parameters and plasma parameters, respectively).

* Significant difference in plasma parameters between 2 and $8 \mathrm{~h}$ after refeeding for each experimental diet $(P<0.05 ;$ Mann-Whitney test).

†SGR $=100 \times((\ln (\mathrm{FBW})-\ln (\mathrm{IBW})) / \mathrm{d})$.

$\ddagger$ Feed efficiency $=$ weight gain $(\mathrm{g}) /$ dry feed intake $(\mathrm{g})$.

$\S$ Feed intake $=\mathrm{g}$ feed intake/fish per $\mathrm{d}$.

|| Plasma parameters measured 2 and $8 \mathrm{~h}$ after refeeding 


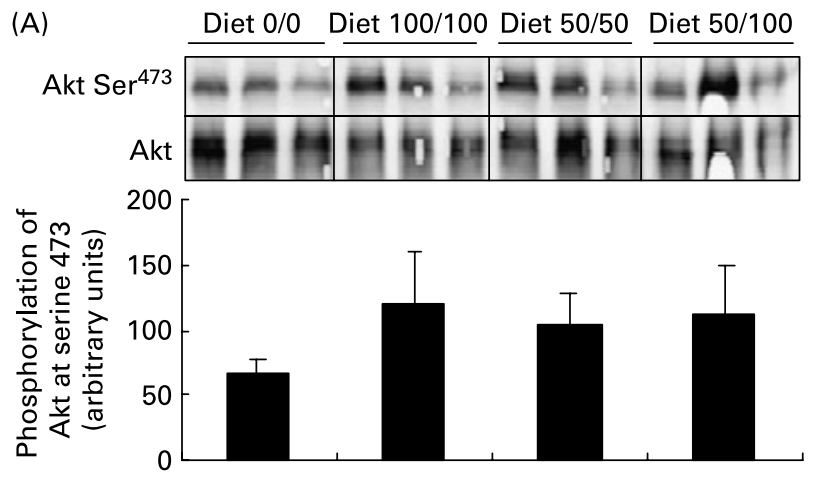

(B) Diet 0/0 Diet 100/100 Diet 50/50 Diet 50/100
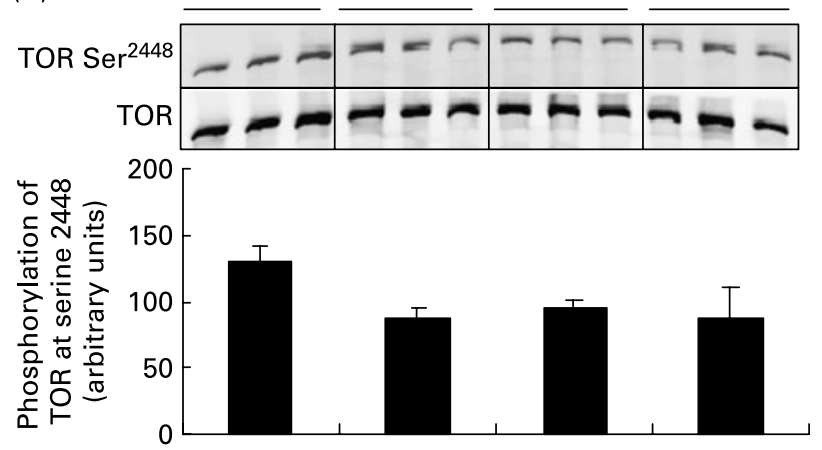

(C) Diet 0/0 Diet 100/100 Diet 50/50 Diet 50/100
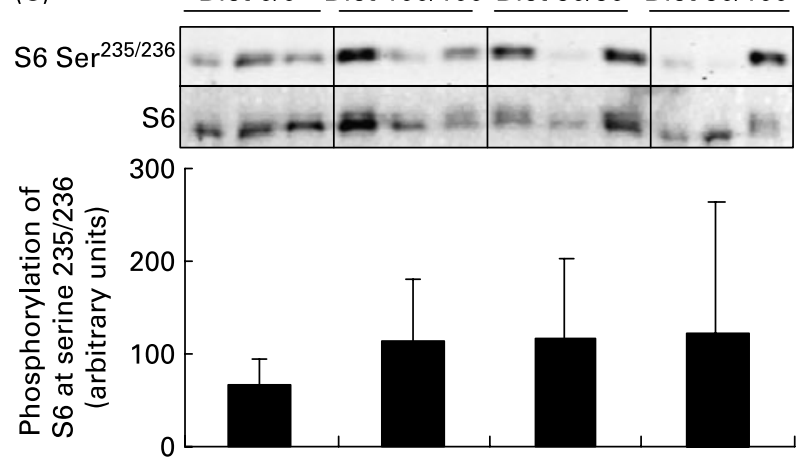

Fig. 3. Effects of diet $0 / 0$ (100\% fish meal (FM), $100 \%$ fish oil (FO)), diet $50 / 50(50 \% \mathrm{FM}$ and $50 \%$ plant protein (PP), $50 \% \mathrm{FO}$ and $50 \%$ vegetable oil (VO)), diet 50/100 (50\% FM and 50\% PP, 100\% VO) and diet 100/100 (100\% PP, $100 \%$ VO) on phosphorylation of protein kinase B (Akt) at Ser ${ }^{473}$ (A), target of rapamycin (TOR) at $\operatorname{Ser}^{2448}$ (B) and S6 at $\operatorname{Ser}^{235 / 236}$ (C) in rainbow trout (Oncorhynchus mykiss) livers, $2 \mathrm{~h}$ after refeeding. The gel was loaded with $20 \mu \mathrm{g}$ of total protein per lane. Phosphorylation levels of Akt at $\mathrm{Ser}^{473}, \mathrm{Akt}, \mathrm{TOR}$ at $\mathrm{Ser}^{2448}, \mathrm{TOR}, \mathrm{S} 6$ at $\mathrm{Ser}^{235 / 236}$ and S6 were quantified and data were normalised to total amounts of Akt, TOR and S6, respectively. Western blots were performed on six individual samples and similar results were obtained; representative blots are shown. Results are means $(n 6)$, with standard errors represented by vertical bars. Results were analysed by the Kruskall-Wallis test; there were no significant differences between the groups.

fed with $40 \%$ PP and $70 \%$ VO showed no statistically significant differences in growth whereas those fed with $80 \% \mathrm{PP}$ and $70 \%$ VO had significantly reduced growth and final body weight. Lower growth performance seemed to be due to both reduced feed intake and lower feed efficiency, particularly with diets devoid of FM and FO. This has been previously reported in another study with rainbow trout fed a low-FM diet ${ }^{(19)}$. Such reduced growth performance is possibly more linked to $\mathrm{PP}$ than to $\mathrm{VO}$ since total substitution of FO by VO does not have any adverse effects on growth in salmonids ${ }^{(10,13,18,19,38)}$. Given the low feed efficiency with PP, our objective was to analyse the effects of such changes on hepatic insulin-nutrient intracellular-signalling pathways as well as on the expression of genes encoding key metabolic enzymes.

We report in the present study for the first time the existence and the nutritional-hormonal regulation of the hepatic Akt-TOR-signalling pathway in the liver of a teleost, as already reported in mammals ${ }^{(23,30)}$. The present study showed that the Akt-TOR-signalling pathway was activated in the livers of refed rainbow trout whereas it was not in trout starved for $5 \mathrm{~d}$, in agreement with the recent characterisation of the TOR-signalling pathway in rainbow trout muscle $^{(36)}$. The refeeding activation of this pathway was probably mainly related to the well-known insulin secretion and postprandial aminoacidaemia peak that occurs in refed sea bass as in refed trout ${ }^{(36,39)}$.

Characterisation of the Akt-TOR-signalling pathway in the livers of rainbow trout allowed us to investigate the effects of dietary FM and FO substitution on the regulation of this transduction pathway. Our findings suggest that replacement of FM and FO in diets had no specific effect on the activation of Akt-TOR-signalling pathways. This could be explained by the fact that, although the four diets differed in terms of ingredient sources, they were similar in terms of macronutrient composition, i.e. they were isonitrogenous, isolipidic and isoenergetic diets.

The expression of only a few genes was affected. Indeed, except for the first isoform of G6Pase, the present study confirms earlier findings showing the absence of significant postprandial inhibition of gluconeogenic gene expression in rainbow trout ${ }^{(40,41)}$. In terms of the glycolytic pathway, GK gene expression was close to the limit of detection and was not stimulated by refeeding. As previously described ${ }^{(42)}$, induction of the regulation of PK, the last enzyme of glycolysis ${ }^{(33)}$, was also absent in refed trout. These results may be due to the low levels of carbohydrates (about 10\%) present in all four diets, leading to only a small increase in postprandial glycaemia (about $1 \mathrm{~g}$ per litre). Indeed, we have previously demonstrated that glucose is essential in the control of GK and PK gene expression in the rainbow trout liver ${ }^{(32)}$. Lipogenesis and lipolysis are known to be under insulin control in mammals, and probably also in fish, since in rainbow trout insulin enhances FAS gene expression while it inhibits expression of CPT1, involved in lipid synthesis and oxidation, respectively ${ }^{(32)}$. The phosphatidylinositol-3-kinase-Akt-signalling pathway mediates insulin regulation of FAS transcription in mammals ${ }^{(25)}$. We demonstrated in the present study that refeeding concomitantly activated Akt and stimulated FAS gene expression, suggesting that refeeding probably induced insulin secretion, and its subsequent signalling pathway resulted in the up-regulation of FAS gene expression. Although we found that the expression of CPT1B mRNA tended to be down-regulated in the refed state $(P=0 \cdot 06)$, we cannot conclude that refeeding modified CPT1 gene expression in our conditions.

As for refeeding, we found no effect of FM and FO substitution on hepatic levels of mitochondrial PEPCK, FBPase, PK, CPT1A and CPT1B mRNA. We demonstrated only that total substitution of FO combined with half substitution of FM 
(B)
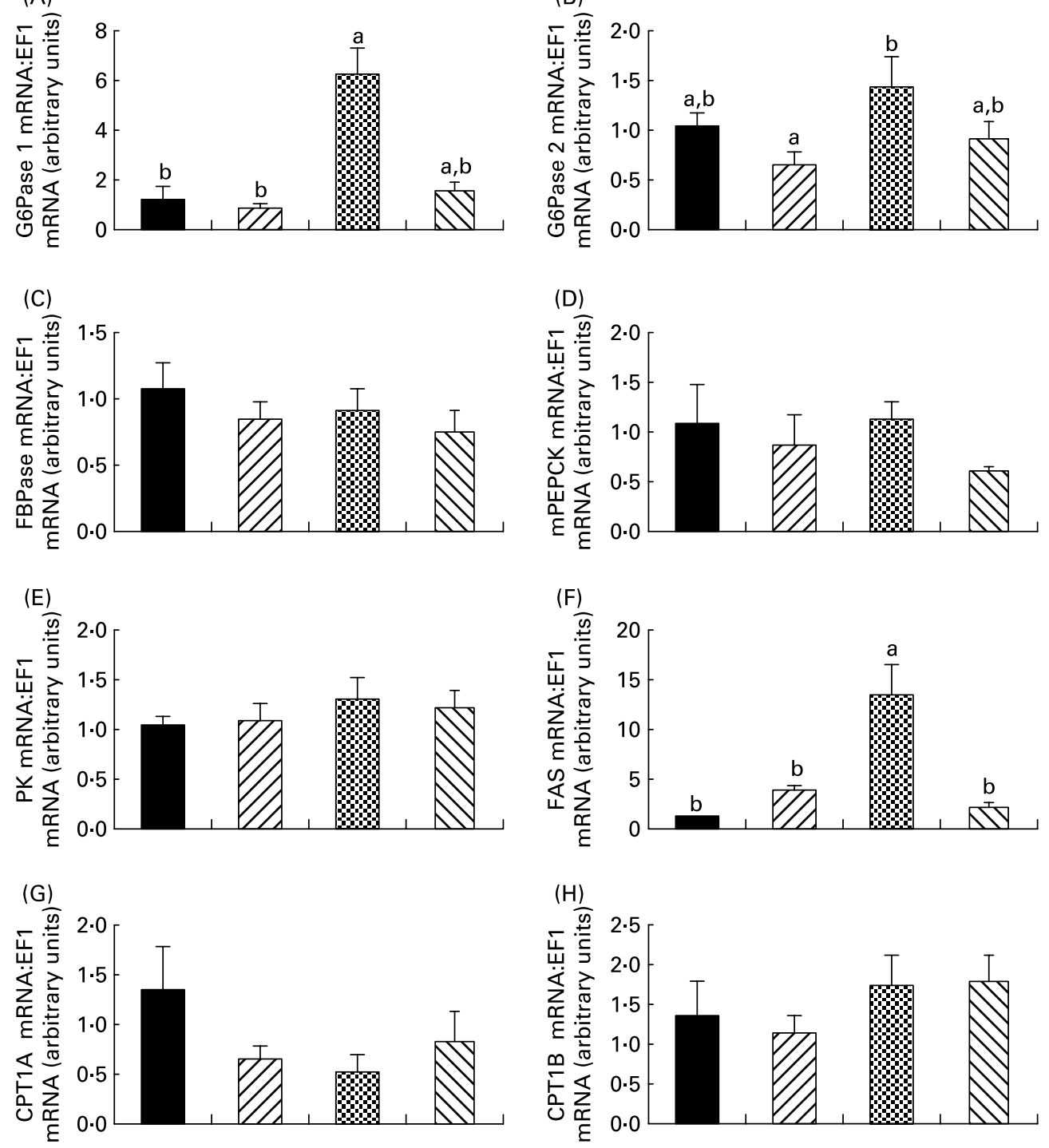

Fig. 4. Effects of of diet $0 / 0$ (100\% fish meal (FM), $100 \%$ fish oil (FO)) (匹), diet $50 / 50$ (50\% FM and $50 \%$ plant protein (PP), $50 \%$ FO and $50 \%$ vegetable oil

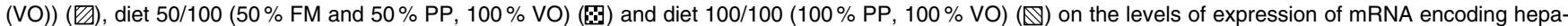
tic metabolism-related genes. Glucose 6-phosphatase isoform 1 (G6Pase-1) (A), glucose 6-phosphatase isoform 2 (G6Pase-2) (B), fructose 1,6-bisphosphatase (FBPase) (C), mitochondrial phosphoenolpyruvate carboxykinase (mPEPCK) (D), pyruvate kinase (PK) (E), fatty acid synthase (FAS) (F), carnitine palmitoyltransferase 1 isoform A (CPT1A) (G) and carnitine palmitoyltransferase 1 isoform B (CPT1B) (H) mRNA levels were estimated using real-time RT-PCR. Expression values were normalised with elongation factor $1 \alpha(E F 1 \alpha)$-expressed transcripts. Results are means $(n 6)$, with standard errors represented by vertical bars. ${ }^{\mathrm{a}, \mathrm{b}}$ Mean values with unlike letters were significantly different $(P<0.05$; Kruskall-Wallis test).

(diet 50/100) significantly increased FAS and G6Pase-1 gene expression compared with the other three groups (and also G6Pase-2 but only compared with diet 50/50). These results were somewhat surprising since we found no effect of total replacement of FM and FO (diet 100/100). It is interesting to note that both genes (G6Pase and FAS) identified as regulated by refeeding were the same as those regulated by diet composition. Although no relationship was found between higher levels of G6Pase-1 mRNA (and potentially increased endogenous glucose production) and plasma glucose level, increased FAS gene expression in fish fed with $100 \% \mathrm{PP}$ and $50 \%$ VO may have been related to the higher levels of peri-visceral fat accumulation observed in fish fed with this diet (data not shown). Finally, compared with previous studies based on the partial replacement of FM or FO in the rainbow trout diet, especially those analysing hepatic transcriptomes $^{(19)}$, we confirmed that plant-based diets had no drastic effects on glucose or lipid metabolism at a molecular level.

In conclusion, we showed that, despite a significant decrease on growth performance of combined FM and FO substitution by plant ingredients in rainbow trout diets, hepatic metabolism-related gene expression was weakly affected. These results are in accordance with a recent complementary study showing that the same diet substitutions weakly modified hepatic transcriptomic profiles ${ }^{(43)}$. Similarly, as indicated by the analysis of the Akt-TOR-signalling pathway, insulin and nutrient transduction signals were not affected by such gross dietary changes, suggesting that modifications which could explain lower growth performance in fish fed $100 \%$ plant products may occur in other metabolic processes. 


\section{Acknowledgements}

We thank C. Vachot for her excellent technical assistance, and F. Terrier, Y. Hontang and F. Sandres for fish rearing in the INRA experimental farm (Donzacq, France).

The present study was supported by the European Union 6th Framework project (contract no. 016249-2, Sustainable aquafeeds to maximise the health benefits of farmed fish for consumers - AQUAMAX) and the Aquitaine Region (no. CCRRDT-20051303004AB). The AQUAMAX European project (contract no. 016249-2) also provided M. L. with a fellowship. S. Polakof was the recipient of a predoctoral fellowship from the Xunta de Galicia (Program Maria Barbeito).

M. L. was responsible for the writing of the manuscript. M. L. and I. S. generated Western blot analysis data. E. P.-J., S. Polakof and M. L. generated the quantitative RTPCR data. I. G. was in charge of zootechnical parameter analysis. G. C., F. M. and S. K. were responsible for the design of the diets and conducted the nutritional experiments in fish. S. S.-C. and S. Panserat were responsible for project development, and drafted and corrected the manuscript. S. S.-C. is the corresponding author.

There are no conflicts of interest.

\section{References}

1. Committee on Animal Nutrition, Board of Agriculture \& National Research Council (1993) Nutrient Requirement of Fish. Washington, DC: National Academic Press.

2. Sargent JR \& Tacon AG (1999) Development of farmed fish: a nutritionally necessary alternative to meat. Proc Nutr Soc 58, 377-383.

3. Naylor RL, Goldburg RJ, Primavera JH, et al. (2000) Effect of aquaculture on world fish supplies. Nature 405, 1017-1024.

4. New MB \& Wijkstroem UN (2002) Use of Fishmeal and Fish Oil in Aquafeeds. Further Throughts on the Fishmeal Trap. Food and Agriculture Organization Fisheries Circular no. 975. Rome: FAO.

5. Gatlin DM, Barrows FT, Brown P, et al. (2007) Expanding the utilization of sustainable plant products in aquafeeds: a review. Aquaculture Res 38, 551-579.

6. Francis G, Makkar HPS \& Becker K (2001) Antinutritional factors present in plant-derived alternate fish feed ingredients and their effects in fish. Aquaculture 199, 197-227.

7. Bell JG, Tocher DR, Henderson RJ, et al. (2003) Altered fatty acid compositions in Atlantic salmon (Salmo salar) fed diets containing linseed and rapeseed oils can be partially restored by a subsequent fish oil finishing diet. $J$ Nutr 133, 2793-2801.

8. Glencross BD, Hawkins WE \& Curnow JG (2003) Restoration of the fatty acid composition of red seabream (Pagrus auratus) using a fish oil finishing diet after grow-out on plant oil based diets. Aquaculture Nutr 9, 409-418.

9. Regost C, Arzel J, Cardinal M, et al. (2003) Total replacement of fish oil by soybean or linseed oil with a return to fish oil in turbot (Psetta maxima) 2. Flesh quality properties. Aquaculture 220, 737-747.

10. Bell JG, Henderson RJ, Tocher DR, et al. (2002) Substituting fish oil with crude palm oil in the diet of Atlantic salmon (Salmo salar) affects muscle fatty acid composition and hepatic fatty acid metabolism. J Nutr 132, 222-230.

11. Torstensen BE, Lie O \& Froyland L (2000) Lipid metabolism and tissue composition in Atlantic salmon (Salmo salar L.) - effects of capelin oil, palm oil, and oleic acid-enriched sunflower oil as dietary lipid sources. Lipids 35, 653-664.
12. Menoyo D, Lopez-Bote CJ, Obach A, et al. (2005) Effect of dietary fish oil substitution with linseed oil on the performance, tissue fatty acid profile, metabolism, and oxidative stability of Atlantic salmon. J Anim Sci 83, 2853-2862.

13. Kaushik SJ, Cravedi JP, Lalles JP, et al. (1995) Partial or total replacement of fish-meal by soybean protein on growth, proteinutilization, potential estrogenic or antigenic effects, cholesterolemia and flesh quality in rainbow-trout, Oncorhynchus-mykiss. Aquaculture 133, 257-274.

14. Kaushik SJ, Coves D, Dutto G, et al. (2004) Almost total replacement of fish meal by plant protein sources in the diet of a marine teleost, the European seabass, Dicentrarchus labrax. Aquaculture 230, 391-404.

15. Gomez-Requeni $\mathrm{P}$, Mingarro $\mathrm{M}$, Calduch-Giner JA, et al. (2004) Protein growth performance, amino acid utilisation and somatotropic axis responsiveness to fish meal replacement by plant protein sources in gilthead sea bream (Sparus aurata). Aquaculture 232, 493-510.

16. Watanabe T, Aoki H, Shimamoto K, et al. (1998) A trial to culture yellowtail with non-fishmeal diets. Fish Sci 64, 505-512.

17. Watanabe T, Verakunpiriya V, Watanabe K, et al. (1997) Feeding of rainbow trout with non-fish meal diets. Fish Sci 63, $258-266$.

18. Vilhelmsson OT, Martin SA, Medale F, et al. (2004) Dietary plant-protein substitution affects hepatic metabolism in rainbow trout (Oncorhynchus mykiss). Br J Nutr 92, 71-80.

19. Panserat S, Kolditz C, Richard N, et al. (2008) Hepatic gene expression profiles in juvenile rainbow trout (Oncorhynchus mykiss) fed fishmeal or fish oil-free diets. $\mathrm{Br} J$ Nutr 100, 953-967.

20. Leaver MJ, Villeneuve LA, Obach A, et al. (2008) Functional genomics reveals increases in cholesterol biosynthetic genes and highly unsaturated fatty acid biosynthesis after dietary substitution of fish oil with vegetable oils in Atlantic salmon (Salmo salar). BMC Genomics 9, 299.

21. Jordal AE, Torstensen BE, Tsoi S, et al. (2005) Dietary rapeseed oil affects the expression of genes involved in hepatic lipid metabolism in Atlantic salmon (Salmo salar L.). J Nutr 135, 2355-2361.

22. Barrows FT, Bellis D, Krogdahl ÃS, et al. (2008) Report of the Plant Products in Aquafeed Strategic Planning Workshop: an integrated, interdisciplinary research roadmap for increasing utilization of plant feedstuffs in diets for carnivorous fish. Rev Fish Sci 16, 449-455.

23. Taniguchi CM, Emanuelli B \& Kahn CR (2006) Critical nodes in signalling pathways: insights into insulin action. Nat Rev Mol Cell Biol 7, 85-96.

24. Barthel A \& Schmoll D (2003) Novel concepts in insulin regulation of hepatic gluconeogenesis. Am J Physiol Endocrinol Metab 285, E685-E692.

25. Sul HS, Latasa MJ, Moon Y, et al. (2000) Regulation of the fatty acid synthase promoter by insulin. $J$ Nutr 130, 315S-320S.

26. Liao J, Barthel A, Nakatani K, et al. (1998) Activation of protein kinase B/Akt is sufficient to repress the glucocorticoid and cAMP induction of phosphoenolpyruvate carboxykinase gene. J Biol Chem 273, 27320-27324.

27. Schmoll D (2000) Regulation of glucose-6-phosphatase gene expression by protein kinase $\mathrm{B} \alpha$ and the forkhead transcription factor FKHR. Evidence for insulin response unit-dependent and -independent effects of insulin on promoter activity. Biol Chem 275, 36324-36333.

28. Dentin R, Denechaud P-D, Benhamed F, et al. (2006) Hepatic gene regulation by glucose and polyunsaturated fatty acids: a role for ChREBP. J Nutr 136, 1145-1149.

29. Tremblay F, Lavigne C, Jacques H, et al. (2007) Role of dietary proteins and amino acids in the pathogenesis of insulin resistance. Апnи Rev Nutr 27, 293-310. 
30. Wullschleger S, Loewith R \& Hall MN (2006) TOR signaling in growth and metabolism. Cell 124, 471-484.

31. Porstmann T, Santos CR, Griffiths B, et al. (2008) SREBP activity is regulated by mTORC 1 and contributes to Akt-dependent cell growth. Cell Metab 8, 224-236.

32. Plagnes-Juan E, Lansard M, Seiliez I, et al. (2008) Insulin regulates the expression of several metabolism-related genes in the liver and primary hepatocytes of rainbow trout (Oncorhynchus mykiss). J Exp Biol 211, 2510-2518.

33. Towle HC, Kaytor EN \& Shih H (1997) Regulation of the expression of lipogenic enzyme genes by carbohydrate. Annu Rev Nutr 17, 405-433.

34. Smith S, Witkowski A \& Joshi AK (2003) Structural and functional organization of the animal fatty acid synthase. Prog Lipid Res 42, 289-317.

35. Pfaffl MW (2001) A new mathematical model for relative quantification in real-time RT-PCR. Nucleic Acids Res 29, E45.

36. Seiliez I, Gabillard JC, Skiba-Cassy S, et al. (2008) An in vivo and in vitro assessment of TOR signaling cascade in rainbow trout (Oncorhynchus mykiss). Am J Physiol Regul Integr Comp Physiol 295, R329-R335.

37. Torstensen BE, Espe M, Sanden M, et al. (2008) Novel production of Atlantic salmon (Salmo salar) protein based on combined replacement of fish meal and fish oil with plant meal and vegetable oil blends. Aquaculture 285, 193-200.
38. Richard N, Kaushik S, Larroquet L, et al. (2006) Replacing dietary fish oil by vegetable oils has little effect on lipogenesis, lipid transport and tissue lipid uptake in rainbow trout (Oncorhynchus mykiss). Br J Nutr 96, 299-309.

39. Gutierrez J, Carrillo M, Zanuy S, et al. (1984) Daily rhythms of insulin and glucose levels in the plasma of sea bass Dicentrarchus labrax after experimental feeding. Gen Comp Endocrinol 55, 393-397.

40. Panserat S, Medale F, Breque J, et al. (2000) Lack of significant long-term effect of dietary carbohydrates on hepatic glucose-6phosphatase expression in rainbow trout (Oncorhynchus mykiss). J Nutr Biochem 11, 22-29.

41. Panserat S, Plagnes-Juan E, Breque J, et al. (2001) Hepatic phosphoenolpyruvate carboxykinase gene expression is not repressed by dietary carbohydrates in rainbow trout (Oncorhynchus mykiss). J Exp Biol 204, 359-365.

42. Panserat S, Plagnes-Juan E \& Kaushik S (2001) Nutritional regulation and tissue specificity of gene expression for proteins involved in hepatic glucose metabolism in rainbow trout (Oncorhynchus mykiss). J Exp Biol 204, 2351-2360.

43. Panserat S, Hortopan GA, Plagnes-Juan E, et al. (2009) Differential gene expression after total replacement of dietary fish meal and fish oil by plant products in rainbow trout (Oncorhynchus mykiss) liver. Aquaculture 294, $123-131$. 